Human and Ecological Risk Assessment: Vol. 7, No. 5, pp. 1247-1254 (2001)

\title{
Large-Scale Temperature Patterns in Past Centuries: Implications for North American Climate Change
}

\author{
Michael E. Mann \\ Department of Environmental Sciences, University of Virginia, Charlottesville, \\ Virginia 22902 USA; mann@virginia.edu
}

\begin{abstract}
Recent climate reconstructions are analyzed specifically for insights into those patterns of climate variability in past centuries with greatest impact on the North American region. Regional variability, largely associated with the El Nino/Southern Oscillation (ENSO) phenomenon, the North Atlantic Oscillation (NAO), and multidecadal patterns of natural variability, are found to mask the emergence of an anthropogenic temperature signal in North America. Substantial recent temperature anomalies may however indicate a possible recent emergence of this signal in the region. Multidecadal North Atlantic variability is likely to positively reinforce any anthropogenic warming over substantial parts of North America in coming decades. The recent magnitudes of El Nino events appear to be unprecedented over the past several centuries. These recent changes, if anthropogenic in nature, may outweigh the projection of larger-scale climate change patterns onto the region in a climate change scenario. The implications of such changes for North America, however, are not yet clear. These observations suggest caution in assessing regional climate change scenarios in North America without a detailed consideration of possible anthropogenic changes in climate patterns influencing the region.
\end{abstract}

Key Words: North Atlantic Oscillation, El Nino, climate change, North America.

\section{INTRODUCTION}

It is likely that anthropogenic climate forcing will most strongly impact particular regions through its influences on existing natural patterns of climate variability such as El Nino and the North Atlantic Oscillation (e.g., Corti et al. 1999). An examination of past patterns of climate variation can thus usefully frame our assessment of possible future regional climate change scenarios. With the latest available evidence, it is now possible to estimate spatial patterns of large-scale climate change during the past several centuries (Briffa 2000; Mann et al. 1998, 1999, 2000a,b; Jones et al. 1998). I focus here on recent climate reconstructions of Mann and colleagues, that have used "multiproxy" networks of high-resolution natural archives such as tree rings, ice cores, an corals, combined with long historical and instrumental records, to

$1080-7039 / 01 / \$ .50$

(C) 2001 by ASP 
reconstruct several centuries to a millennium back in time, large-scale surface temperature patterns (Mann et al. 1999, 2000a,b), indices of the El Nino/Southern Oscillation ("ENSO") phenomenon (Mann et al. 2000a,b), the North Atlantic Oscillation (Mann 2001; Cullen et al. 2001), and patterns of natural (Delworth and Mann 2000) and externally-forced (Waple et al. 2001) climate variability. These reconstructions are used to draw inferences into the long-term patterns of climate variability influencing North America and implications for future climate change in the region.

\section{DATA AND METHODS}

The Mann et al. approach to paleoclimate reconstruction has been discussed elsewhere in more detail (see Mann et al. 1998, 1999, 2000a,b). The method involves a multivariate calibration of the leading eigenvectors of the 20th century surface temperature record (see Figure 1; the eigenvectors are calculated from the shaded region during the period 1902-1993) against a global network of diverse proxy indicators (see Figure 2). This approach exploits the large-scale structure and complementary seasonal and climatic information in a diverse network of climate proxy indicators in reconstructing past global surface temperature patterns. Significant skill in these reconstructions has been indicated in independent cross-validation exercises (see Mann et al. 1998, 1999, 2000a,b) and appropriate self-consistent uncertainties have been estimated back in time. The annual-mean reconstructions of Mann et al. (1998) have been extended recently to include distinct warm and cold-season reconstructions (Mann et al. 2000b). The underlying principle behind this approach is that networks of proxy climate indicators combined with the few available long instrumental or historical climate records can be used to capture the variations in the main patterns of temperature variation in the modern instrumental record. These patterns can then be combined to yield estimates of the surface temperature field back in time. From the reconstructed surface temperature patterns, global, hemispheric, or regional mean averages of interest are readily evaluated.

The methodology employed in these proxy-based climate reconstructions assumes that each proxy record exhibits a linear relationship with one or more of the principal components (PCs) of the instrumental surface temperature record. The methodology does not assume that the proxy record is itself necessarily an indicator of temperature. Only carefully screened records with annual resolution and dating were used. For the period after A.D. 1820, when all 112 records were available, it was possible to skillfully reconstruct $11 \mathrm{PCs}$, or temperature patterns, calibrating (and cross-validating) between 30 to $40 \%$ of the total instrumental surface temperature variance, and 70 to $80 \%$ of the instrumental variance in Northern Hemisphere $(\mathrm{NH})$ mean temperature. As the dataset becomes sparser for earlier times, the number of patterns that can be skillfully reconstructed decreases. Back to AD 1000 roughly $40 \%$ of the variance in $\mathrm{NH}$ is resolved in calibration and verification. The detailed reconstructions are available online in the electronic journal Earth Interactions (Mann et al. 2000b).

The salient long-term features of the NH reconstruction (Figure 3) are a steady decline of about $0.02^{\circ} \mathrm{C} /$ century from A.D. 1000 to the mid-19th century, and a sudden, rapid warming during the 20th century. This warming has been attributed 


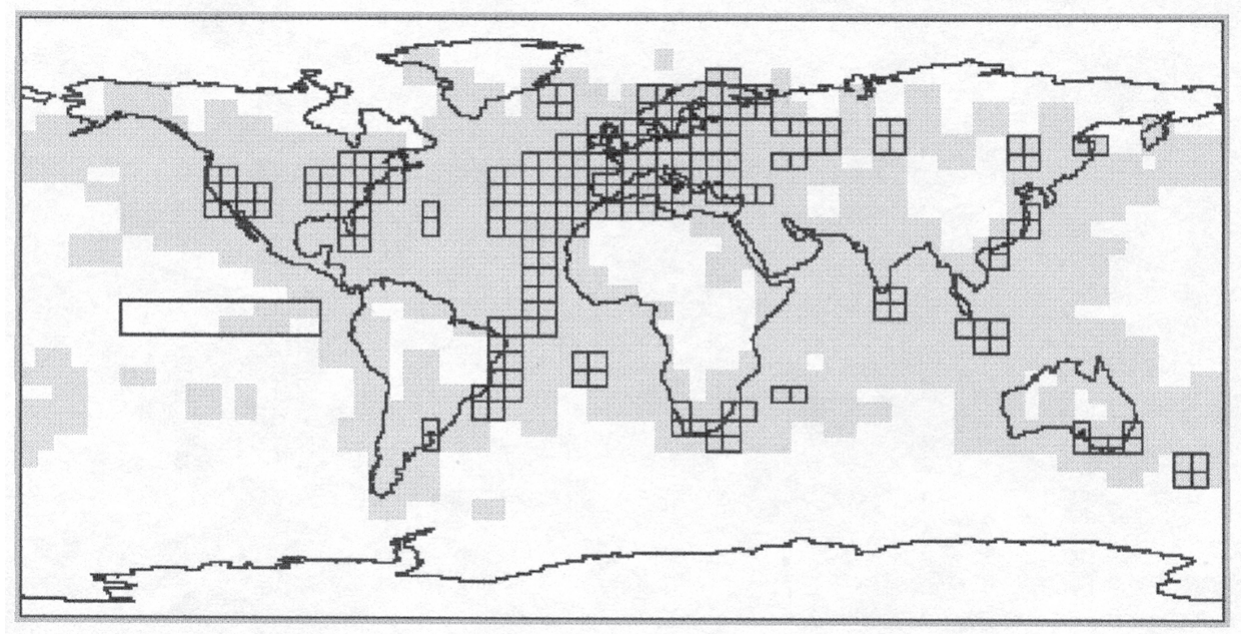

Figure 1. Instrumental temperature data: shaded area used for calibration, 1902-1980; squares used for verification 1854-1901.

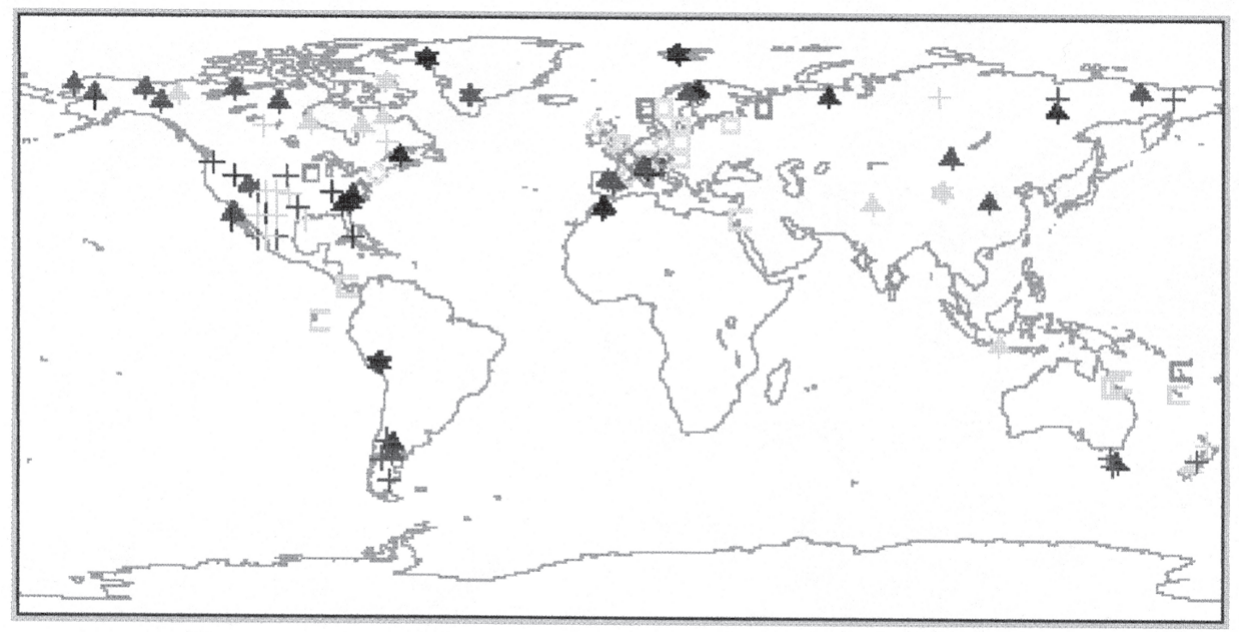

Figure 2. Natural archives used in reconstruction to AD 1400. Tree symbol tree-ring; plus - PCs of dense tree-ring networks, star — ice core/ice melt, 'C' — coral, square early instrumental/historical — temperature — diamond — instrumental precipitation. 
to anthropogenic forcing, while much of the residual decadal-scale variability has been attributed to natural forcing factors such as volcanism and solar irradiance variations (Mann et al. 1998; Crowley and Kim 1999; Crowley 2000; Mann 2000).

\section{TEMPERATURE CHANGES IN NORTH AMERICA}

It is instructive to compare the hemispheric trends shown in Figure 3 with the more regional temperature trends of North America (Plate 1; the North American series is constructed by areally averaging the temperature reconstructions over the North American gridpoints shown in Figure 1; owing to the loss of spatial degrees of freedom in the reconstructions back in time, it is not possible to meaningfully estimate this regional series prior to about 1750). It is clear that the 19th century was anomalously cold in North America (approximately 0.6 C colder than the Northern Hemisphere on the whole). The subsequent warming trend since the 19th century has thus been somewhat larger for North America than for the hemisphere on the whole (approximately $1.2 \mathrm{C}$ vs. $0.6 \mathrm{C}$ ). The variability in this region is significantly greater than that for the entire hemisphere on almost all timescales, as we would expect from the spatial sampling characteristics of a smaller region. In particular, however, there is considerably enhanced variability on multidecadal-to-century timescales. This results from patterns of natural variability, which have considerable influence on this region, as discussed further below. Such substantial multidecadal and century-scale variability in past centuries has also been noted in patterns of North American continental drought in past centuries (e.g., Hughes and Graumlich 1996; Woodhouse and Overpeck 1998).

Owing to this natural variability, the latter 20th century, while the warmest period in the North American temperature reconstruction, is not clearly outside the range of natural variability $(e . g$, the mid 20th century warmth is similar to that of the late 18 th century in the reconstruction). However, the 1990s are the warmest decade in the reconstructed history of the past 250 years, suggesting the possible emergence of a warming trend from the background of noise in the recent past. The comparison of hemispheric and regional temperature trends emphasizes the importance of regional overprints of natural variability at these spatial scales, as discussed further below.

\section{THE NORTH ATLANTIC OSCILLATION (NAO) AND RELATED PATTERNS OF VARIABILITY}

The NAO is one primary pattern of interannual-to-decadal climate variability in the Northern Hemisphere. The influence is largely restricted to the winter season, and regions in or downstream from the North Atlantic, although there is a modest influence on eastern North America (Hurrrell 1996). A prolonged positive anomaly in the NAO has been observed in recent decades (Hurrell and Van Loon 1997). This anomaly has been argued to be outside the range of natural variability as estimated from model simulations (Osborn et al. 1999). Proxy (Cullen et al. 2001) and long instrumental-based (Jones et al. 1997; Luterbacher et al. 1999) extensions of the

* $\quad$ Plates appear following page 1247. 
Temperature Patterns in Past Centuries

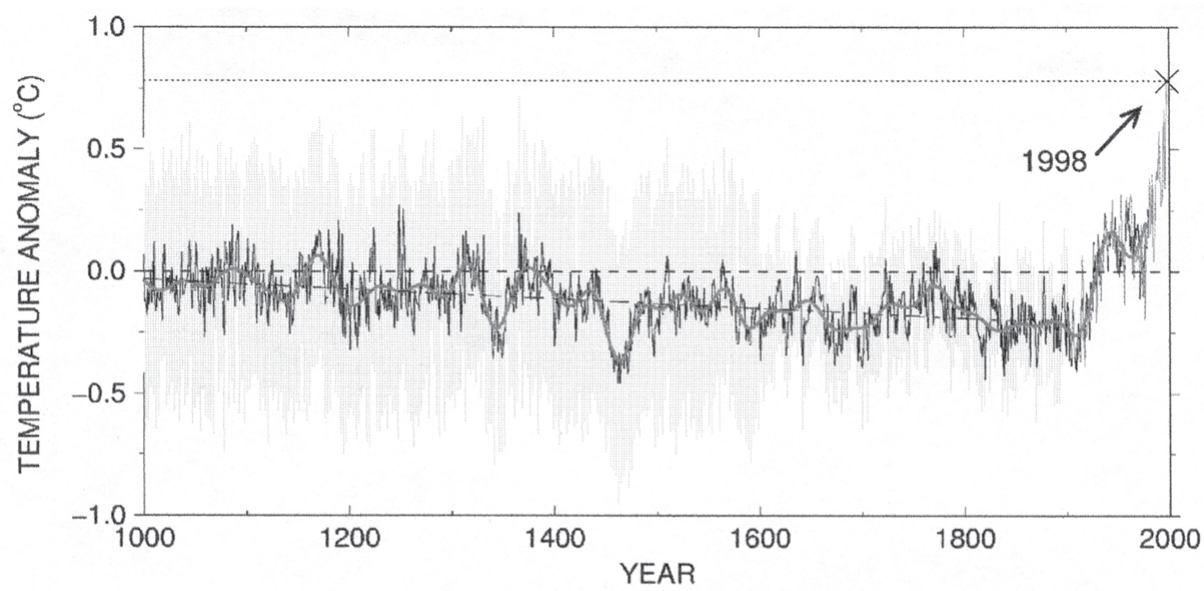

$$
\begin{aligned}
& \text { - reconstruction (AD 1000-1980) } \\
& \text { instrumental data (AD 1902-1998) } \\
& \text { - . - calibration period (AD 1902-1980) mean } \\
& \text { - reconstruction (40 year smoothed) } \\
& \text { linear trend (AD 1000-1850) }
\end{aligned}
$$

Figure 3. Northern Hemisphere mean annual temperature. The shaded band indicates 95\% confidence limits. Note that uncertainties increase back in time. 1998 value is shown for comparison [(from Mann et al. 1999, (C) American Geophysical Union].

NAO back through the early 19th and 18th centuries, however, show similar, if not quite as large, anomalies in the past, and it remains unclear whether these recent trends are anthropogenic in nature.

Keigwin and Pickart (2000) suggest that NAO anomalies coincided with largescale climate trends in the past millennium. If so, the NAO may have imprinted a stronger signal of the "Little Ice Age' and "Medieval Warm Period" in parts of Europe and North America (see Mann 2000). Demenocal et al. (2000) note, however, that a more basin-wide pattern of warming and cooling in the North Atlantic appears to have accompanied these changes. Such a basin-wide pattern related to, but distinct from, the NAO has indeed been implicated in recent analyses of multidecadal and century-scale variability in paleoclimate reconstructions (Mann et $a l .1995,1998)$ and coupled ocean-atmosphere model simulations (Delworth and Mann 2000).

These latter studies suggest a multidecadal pattern of climate variability associated with coupled ocean-atmosphere processes, with a distinct projection onto North American temperature changes on multidecadal and century timescales. Shown (Plate $2^{*}$ ) is one assessment of the spatial (upper panel) and temporal (lower panel) signature of this multidecadal signal. Note the downturn in recent decades, implying an overprint of cooling in North America in recent decades, which has likely masked the global warming signal. Indeed it is quite likely that a reversal of this downturn is taking place, which implies enhanced warming in North America and the tropical North Atlantic in the coming decades. The combination of such 
natural warming on top of an emerging anthropogenic warming could have significant consequences for regional temperature patterns in eastern North America. Moreover, the associated enhanced warming in the tropical North Atlantic could lead to increased frequency and intensity of Atlantic tropical storms influencing the East Coast of the United States (see Kerr 2000).

\section{ENSO INFLUENCES}

The Niño-3 index of ENSO-related variability (Figure 6) is diagnosed by averaging the cold-season temperature reconstructions (see Mann et al. 2000b) over the Niño-3 region of the tropical Pacific (the rectangular region in the eastern equatorial Pacific shown in Figure 1). This index resolves 60 to $70 \%$ of the observed Niño3 variance during the 20th century and, as shown in Plate $3^{*}$, correlates highly $(r=0.64)$ with the largely independent winter Southern Oscillation Index (SOI) series of Stahle et al. (1998). In contrast to the Northern Hemisphere series, there is no clear trend in the Niño-3 index in recent decades. However, the two single largest events appear to have occurred during the past two decades (the '97/'98 and ' 82 /' 83 events are nominally the largest two events in the chronology, and both are outside the estimated uncertainty range in the reconstructions). Timmermann et al. (1999) argue that such behavior is consistent with recent model simulations of the response of the tropical Pacific to anthropogenic climate change. It is thus quite possible that this unusual recent behavior of ENSO is anthropogenic in nature.

The implications for North America of such possible changes in ENSO are more difficult to assess, as the extratropical teleconnections of ENSO into North America are themselves not necessarily stationary on multidecadal timescales (e.g., Cole and Cook 1998; Mann et al. 2000a). Shown in Plate 4 (from Mann et al. 2000a) is the characteristic correlation pattern of the cold-season Niño-3 index against annualmean global surface temperatures, in distinct 50 year intervals back through 1650 . The variability in the North American teleconnections, particularly in the Eastern United States, is especially evident, and even the sign of the temperature signature of ENSO appears to be variable on multidecadal timescales in the latter region. Thus, while it is quite possible that anthropogenic forcing may increase the magnitude and frequency of warm ENSO events (i.e., El Niños), the teleconnections into many parts of North America are not robust enough to obviate the likely influence of such changes.

\section{CONCLUSIONS}

It is clear that climate changes in North America, let alone particular sub-regions of North America such as the eastern United States, exhibit far greater variability on nearly all timescales than the Northern Hemisphere on the whole. While multidecadal natural variability appears to have masked anthropogenic warming in North America in past decades, it appears that a warming signal in this region is now emerging. In fact, the combination of a positive upturn in the dominant pattern of multidecadal natural variability superimposed on an anthropogenic warming trend could lead to a particularly dramatic warming in North America during the next few decades. Related warming in the tropical North Atlantic, moreover, may support an increase 
Temperature Patterns in Past Centuries

in tropical storm activity influencing the east coast of the United States. It is also likely that strong El Nino episodes may become more prominent, leading to greater interannual extremes of temperature, flood, and drought patterns in North America in coming decades. A proper assessment of environmental risk in North America associated with potential future anthropogenic climate change must take these regional factors into account.

\section{REFERENCES}

Briffa KR. 2000. Annual climate variability in the Holocene: interpreting the message of ancient trees. Quaternary Sci Rev 19:87-105

Cole JE and Cook ER. 1998. The changing relationship between ENSO variability and moisture balance in the continental United States. Geophysical Res Lett 25:4529-532

Corti S, Molteni F, and Palmer TN. 1999. Signature of recent climate change in frequencies of natural atmospheric circulation regimes. Nature 398:799-802

Crowley TJ. 2000. Causes of climate change of the last 1000 years. Science 289:270-7

Crowley TJ and Kim KY. 1999.

Modeling the temperature response to forced climate change over the last six centuries. Geophysical Res Lett 26:1901-4

Cullen H, D'Arrigo R, Cook E, et al. 2001. Multiproxy-based reconstructions of the North Atlantic Oscillation over the past three centuries. Paleoceanography 15:27-39

Delworth TD and Mann ME. 2000. Observed and simulated multidecadal variability in the North Atlantic. Climate Dynamics 16:661-76

Hughes MK and Graumlich LJ. 1996. Multimillennial dendroclimatic records from western North America. In: Bradley RS, Jones PD, and Jouzel J (eds), Climatic Variations and Forcing Mechanisms of the Last 2000 Years, pp. 109-24. Springer Verlag, Berlin, Germany

Hurrell JW and van Loon H. 1997. Decadal variations in climate associated with the North Atlantic Oscillation. Climatic Change 36:301-26

Jones PD, Jonsson T, and Wheeler D. 1997. Extension to the North Atlantic Oscillation using early instrumental pressure observations from Gibraltar and South-West Iceland. International Journal of Climatology 17:1433-50

Kerr RA. 2000. A North Atlantic climate pacemaker for the centuries. Science 288:1984-6

Mann ME. 2000. Lessons for a new millennium. Science 289:253-4

Mann ME. 2001. Large-scale climate variability and connections with the Middle East in past centuries. Climatic Change (in press)

Mann ME, Bradley RS, and Hughes MK. 1998. Global-scale temperature patterns and climate forcing over the past six centuries. Nature 392:779-87

Mann ME, Bradley RS, and Hughes MK. 1999. Northern hemisphere temperatures during the past millennium: Inferences, uncertainties, and limitations. Geophysical Research Letters 26:759-62

Mann ME, Bradley RS, and Hughes MK. 2000a. Long-term variability in the El Nino Southern Oscillation and associated teleconnections. In: Diaz HF and Markgraf V (eds), El Niño and the Southern Oscillation: Multiscale Variability and its Impacts on Natural Ecosystems and Society, pp 357-412. Cambridge University Press, Cambridge, UK

Mann ME, et al. 2000b. Annual Temperature Patterns in Past Centuries: An interactive presentation. Earth Interactions 4-4:1-29

Osborn TJ, Briffa KR, Tett SFB, et al. 1999. Evaluation of the North Atlantic Oscillation as simulated by a coupled climate model. Climate Dynamics 15:685-702

Stahle DW, D’Arrigo RD, Krusic PJ, et al. 1998. Experimental dendroclimatic reconstruction of the Southern Oscillation. Bull Am Meteorological Soc 79:2137-52 


\section{Mann}

Timmermann A, Oberhuber J, Bacher A, et al. 1999. Increased El Nino frequency in a climate model forced by future greenhouse warming. Nature 398:694-7

Waple A, Mann ME, and Bradley RS. 2001. Long-term patterns of solar irradiance forcing in model experiments and proxy-based surface temperature reconstructions. Climate Dynamics (in press) 